\title{
BENDING TRIANGULAR FINITE ELEMENT WITH A FICTITIOUS FOURTH NODE BASED ON THE STRAIN APPROACH
}

\author{
Mohamed Himeur ${ }^{1}$ \& Mohamed Guenfoud ${ }^{2}$ \\ Laboratoire de Génie Civil et d'Hydraulique, Université de Guelma, Algérie \\ bet_himeur@yahoo.fr \& Gue2905m@yahoo.fr,
}

\begin{abstract}
We present a new plate bending triangular finite element. It is developed in perspective to building shell elements. Its formulation uses concepts related to the deformation approach, the fourth fictitious node, the static condensation and analytic integration. It is based on the assumptions of the theory of thin plates (Kirchhoff theory). The approach has resulted in a bending plate finite element (HIMEUR) competitive, robust and efficient.
\end{abstract}

Keywords: Finite element, Strain formulation, analytical integration, static condensation, thin plate

\section{INTRODUCTION}

Complex structures (shell) are frequently encountered in various fields. The development of simple and efficient finite element for the analysis of these structures is a major thrust of scientific research in solid mechanics. But problems are often encountered difficulty making the achievement of objectives. The major constraints observed are often linked:

- Aspects of incompatible displacement fields when adding the membrane elements with those of plaque.

- The phenomena of shear locking and membrane "shear locking" and "membrane locking".

- The numerical problems induced by the absence of the "sixth DOF" in the case of co-planar elements.

- The numerical problems associated with numerical integration.

The objective of this research is, "the formulation of shell finite element formulation based on the deformation" whose purpose is to circumvent these difficulties one hand, and the construction of finite element shell simple and effective for the analysis of complex structures. To do this, we enriched our approach with the concepts and development techniques based on the adoption of the "deformation approach", introducing a "fictitious fourth node" in the triangular element whose degrees freedom of correspondents are subsequently eliminated at the elementary stiffness matrix by the technique of static condensation, the use of "analytic integration 'for evaluating the stiffness matrix.
Early work [HIM08] led to the construction of triangular membrane finite elements can be combined easily with inflectional elements (slabs, beams and shells).

These elements are:

- $\quad$ "T3_Kteta" [HIM08], in which the unknown nodal rotation is obtained by adding to the stiffness matrix of "CST "(as expressed in strain) stiffness matrix associated with rotation around the normal (drilling rotation). Starting from the approach of [PRO00], this matrix "rotation" is obtained by minimizing the strain energy of rotation around the normal.

- "T43" [HGM08] and "T43_Eq" [HIM08] are triangular finites elements with central node disrupted. They are characterized by the presence of unknown nodal rotation defined by derivation of displacement fields (drilling rotation). The interpolation functions are those used by Sabir [SAB85] for element "T43" and those obtained from equilibrium conditions for the element "T43_Eq" (dual harmonic polynomials selected from the solutions given by the development the Airy function [TEO82]).

"T42"and "T42_Eq" [HIM08] that does not have an unknown nodal rotation,

This work is a series of our research, focusing this time on the development of finite element triangular plate. The triangular finite element inflected with a fictitious fourth node based on the approach to deformation is the culmination of this work. We call it «HIMEUR». 
This element is formulated using the approach to deformation. The interpolation functions of the deformation fields, therefore the displacements and stresses are developed using Pascal's triangle. It is a triangular element to which we added a fourth node dummy positioned outside and away from the triangle. This position, outside, is chosen to avoid the relaxation of the stiffness matrix resulting in an overestimation of the nodal displacements. The degrees of freedom corresponding to the fourth node are then eliminated by static condensation of the stiffness matrix at the elementary level. So the main interest of this fictitious node resides in the enrichment field trips ( $p$ refinement: increase in the degree of the polynomial interpolation), and is, therefore, greater precision in the approximation of the solution. The corresponding variational criterion is that of the total potential energy. The analytical integration for the evaluation of the stiffness matrix is highly attractive to avoid the loss of convergence phenomenon observed in isoperimetric elements (using numerical integration) that are very sensitive (their convergence is conditioned by a regular mesh undistorted). The assumptions of this formulation are those of the thin plate theory (Kirchhoff's theory) by neglecting the transverse shear.

To validate the new element HIMEUR, we tested a set of test cases. For each test case, the result is compared, first, to the corresponding reference solution, and secondly, the solution given by certain elements of thin plate located in the literature. Behaviour in pure bending (bending to the dominant shear) is processed through the example used by J.L. Batoz and Dhatt G. [BAT90]. This test is very useful to evaluate levels of convergence, robustness and performance of our element. The behaviour of this element relative to the transverse shear is analyzed using the example treated Guenfoud [GUE93] Belarbi and Sharif [BEL99]. Finally we submitted our element tests proposed by Robinson [ROB78] to gauge their behaviour to aspects of torsion.

Generally, the approach in our development has resulted in a plate finite element (HIMEUR) competitive, robust and efficient. This appears, first, through his excellent pace of convergence towards the reference solution, and secondly, through the performance of his behaviour towards other triangular plate elements in the existing literature: DKT, HCT [BAT90], $\mathrm{C}^{\mathrm{O}}$ [BEL84], and ANST3 ANST6 [GUE90], TRUMP (Argyris) and SRI [SAB00].

\section{BASIC EQUATIONS OF THE THEORY OF THIN PLATES (KIRCHHOFF THEORY)}

\subsection{Kinematics equations}

In figure 1 , the rotations around the two axes $\mathrm{x}$ and $\mathrm{y}$ is denoted $\theta x$ and $\theta y$ and slopes in both directions are defined by the variables $\beta \mathrm{x}$ and $\beta y$, with:

$$
\beta_{\mathrm{x}}=\theta_{y} \quad \beta_{y}=-\theta_{x}
$$

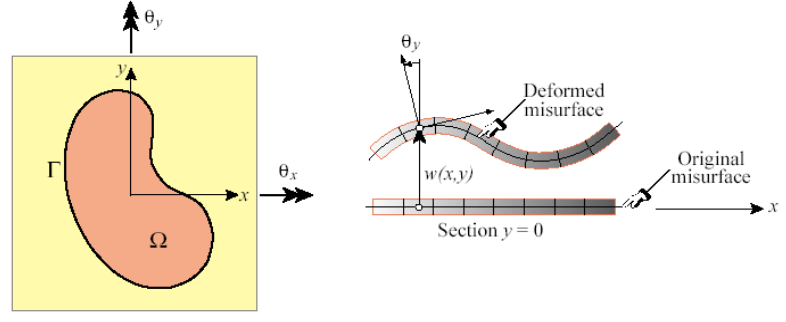

Figure 1 : Deformation of a plate bending (Kirchhoff Theory)

The assumption of the cross section implies a linear variation of displacement over the thickness of the plate. This translates into:

$$
\begin{aligned}
& u(x, y, z)=z \beta_{x}(x, y)=z \theta_{y}(x, y), \\
& v(x, y, z)=z \beta_{y}(x, y)=-z \theta_{x}(x, y)
\end{aligned}
$$

The expressions (02) can decouple the displacement fields $(\mathrm{u}, \mathrm{v})$ that of the arrow (w) which is in reference to the assumptions of Kirchhoff, the only field to define the behaviour of the plate. Thus, the displacements are given by:

$$
\begin{aligned}
& w(x, y, z)=w(x, y) \quad u(x, y, z)=-\frac{\partial w}{\partial x} \\
& v(x, y, z)=-\frac{\partial w}{\partial y}
\end{aligned}
$$

And rotations are given by:

$-\theta_{x}=\beta_{y}=-\frac{\partial w}{\partial y}$

$\theta_{y}=\beta_{x}=-\frac{\partial w}{\partial x}$

The infinitesimal strain tensor is then:

$\varepsilon_{x}=\frac{\partial u}{\partial x}=z \frac{\partial \beta_{x}}{\partial x}=-z \frac{\partial^{2} w}{\partial x^{2}}$

$\varepsilon_{y}=\frac{\partial v}{\partial y}=z \frac{\partial \beta_{y}}{\partial y}=-z \frac{\partial^{2} w}{\partial y^{2}}$

$\gamma_{x y}=\frac{\partial u}{\partial y}+\frac{\partial v}{\partial x}=z\left(\frac{\partial \beta_{x}}{\partial y}+\frac{\partial \beta_{y}}{\partial x}\right)=-2 z \frac{\partial^{2} w}{\partial x \partial y}$

$\gamma_{x z}=\gamma_{y z}=0$

Moments related to the curvatures are given by:

$$
K_{x}=\frac{\partial \beta_{x}}{\partial x}=-\frac{\partial^{2} w}{\partial x^{2}} \quad K_{y}=\frac{\partial \beta_{y}}{\partial y}=-\frac{\partial^{2} w}{\partial y^{2}}
$$




$$
K_{x y}=\left(\frac{\partial \beta_{x}}{\partial y}+\frac{\partial \beta_{y}}{\partial x}\right)=-2 \frac{\partial^{2} w}{\partial x \partial y}
$$

\subsection{Kinematics compatibility conditions}

These conditions were established by St. Venant (1854) [FRE98]. Their satisfaction is required to guarantee the uniqueness of the displacements. The compatibility equations are as developed as follows:

$\frac{\partial^{2} K_{x}}{\partial y^{2}}+\frac{\partial^{2} K_{y}}{\partial x^{2}}=\frac{\partial^{2} K_{x y}}{\partial x \partial y}$

$\frac{\partial^{2} \gamma_{x z}}{\partial x \partial y}-\frac{\partial^{2} \gamma_{y z}}{\partial x^{2}}+\frac{\partial^{2} K_{x y}}{\partial x}=2 \frac{\partial K_{x}}{\partial y}$

$\frac{\partial^{2} \gamma_{y z}}{\partial x \partial y}-\frac{\partial^{2} \gamma_{x z}}{\partial y^{2}}+\frac{\partial^{2} K_{x y}}{\partial y}=2 \frac{\partial K_{y}}{\partial x}(07)$

\subsection{Constitutive law}

In plane state of stress and for isotropic materials, generally accepted hypothesis for the calculation of thin structures (beams, plates and shells), the constitutive law is written:

$$
\left\{\begin{array}{c}
\sigma_{x} \\
\sigma_{y} \\
\tau_{x y}
\end{array}\right\}=\frac{E}{1-v^{2}}\left[\begin{array}{ccc}
1 & v & 0 \\
v & 1 & 0 \\
0 & 0 & \frac{1-v}{2}
\end{array}\right]\left\{\begin{array}{c}
\varepsilon_{x} \\
\varepsilon_{y} \\
\gamma_{x y}
\end{array}\right\} .
$$

This translates in terms of relationship "moment-curvature» by the following equation system:

$$
\begin{aligned}
\left\{\begin{array}{l}
M_{x} \\
M_{y} \\
M_{x y}
\end{array}\right\} & =\frac{E h^{3}}{12\left(1-v^{2}\right)}\left[\begin{array}{ccc}
1 & v & 0 \\
v & 1 & 0 \\
0 & 0 & \frac{1-v}{2}
\end{array}\right]\left\{\begin{array}{l}
K_{x} \\
K_{y} \\
K_{x y}
\end{array}\right\} . \\
& =\frac{E h^{3}}{12\left(1-v^{2}\right)}\left[\begin{array}{ccc}
1 & v & 0 \\
v & 1 & 0 \\
0 & 0 & \frac{1-v}{2}
\end{array}\right]\left\{\begin{array}{l}
-\frac{\partial^{2} w}{\partial x^{2}} \\
-\frac{\partial^{2} w}{\partial y^{2}} \\
-2 \frac{\partial^{2} w}{\partial x \partial y}
\end{array}\right\}
\end{aligned}
$$

\subsection{Equations of equilibrium}

The balance of an element of dimensions $d x \times d y$ is obtained by the balance of forces of internal and external actions. $q d x d y+\left(Q_{x}+\frac{\partial Q_{x}}{\partial x}\right) d y+\left(Q_{y}+\frac{\partial Q_{y}}{\partial y}\right) d x-Q_{x} d y-Q_{y} d x=0$

Where, $Q_{x}$ and $Q_{y}$ are the shear forces in the sections perpendicular to the axes $x$ and $y$ respectively. The expression (10) is simplified to give:

$q+\frac{\partial Q_{x}}{\partial x}+\frac{\partial Q_{y}}{\partial y}=0$

The balance of moments about the axes $\mathrm{x}$ and $\mathrm{y}$ gives:

$$
Q_{x}=\frac{\partial M_{x}}{\partial x}+\frac{\partial M_{x y}}{\partial y} \quad Q_{y}=\frac{\partial M_{y}}{\partial y}+\frac{\partial M_{x y}}{\partial x}
$$

By replacing the $Q x$ and $Q y$ values of equations (11) and (12) in relation (09), the equilibrium condition would result in the displacement function "w" by the following expression:

$\frac{\partial^{4} w}{\partial x^{4}}+2 \frac{\partial^{4} w}{\partial x^{2} \partial y^{2}}+\frac{\partial^{4} w}{\partial y^{4}}-\frac{q}{D}=0$

With

$$
D=\frac{E h^{3}}{12\left(1-v^{2}\right)}
$$

\section{FORMULATION OF THE ELEMENT "HIMEUR"}

\subsection{Shape function}

For rigid body motions (MCR), bending moments are related to zero:

$\mathrm{K}_{\mathrm{x}}=0 \quad \mathrm{~K}_{\mathrm{y}}=0 \quad \mathrm{~K}_{\mathrm{xy}}=0$

By replacing in equations (06) the curves with their values given by equations (14) and after integration, we obtain the displacement fields representing the rigid body motions which are as follows:

$\mathrm{W}=\mathrm{a}_{1}-\mathrm{a}_{2} \cdot \mathrm{x}-\mathrm{a}_{3} y \quad \beta_{x}=\mathrm{a}_{2} \beta_{y}=a_{3}$

With $\mathrm{a}_{2}$ and $\mathrm{a}_{3}$, parameters representing rotations $\theta_{x}$ and $\theta_{y}$ of the rigid body about respective axis " $y "$ and " $x "$ representing the translation and $\mathrm{a}_{1}$ (arrow) of the rigid body along the normal (axis " $z$ ") .

Our element has four nodes (three vertices which we have added a fourth dummy node). Each of its nodes has three degrees of freedom. So the displacement fields, formulated by the use of the model deformation, have 12 independent constants $\left(a_{1}, . ., a_{12}\right)$. The first three $\left(a_{1}, a_{2}, a_{3}\right)$ are used in equations (02) to represent rigid body motions. The other nine $\left(a_{4}, a_{12}\right)$ are used to represent the state of pure bending. They are divided into the deformation interpolation functions to satisfy the equations (07) of kinematics 
compatibility for plane elasticity. Thus, the deformation fields for the higher modes are derived from Pascal's triangle as follows:

$\mathrm{K}_{\mathrm{x}}=\mathrm{a}_{4}+\mathrm{a}_{5} \cdot \mathrm{x}+\mathrm{a}_{6} y+a_{7} x y K_{y}=\mathrm{a}_{8}+\mathrm{a}_{9} \mathrm{x}+\mathrm{a}_{10} y+a_{11} x y$

$K_{x y}=\mathrm{a}_{12}+2 \cdot a_{6} \cdot x+a_{7} \cdot x^{2}+2 \cdot a_{9} \cdot y+a_{11} \cdot y^{2}$

By replacing in equations (06) the curves with their values given by equations (16) and after integration, we obtain the following field trips:

$$
\begin{aligned}
W= & -a_{4} \frac{x^{2}}{2}-a_{5} \frac{x^{3}}{6}-a_{6} \frac{x^{2} y}{2}-a_{7} \frac{x^{3} y}{6}-a_{8} \frac{y^{2}}{2} \\
& -a_{9} \frac{x y^{2}}{2}-a_{10} \frac{y^{3}}{6}-a_{11} \frac{x y^{3}}{6}-a_{12} \frac{x y}{2} \\
\beta_{x}= & a_{4} x+a_{5} \frac{x^{2}}{2}+a_{6} x y+a_{7} \frac{x^{2} y}{2}+a_{9} \frac{y^{2}}{2} \\
& +a_{11} \frac{y^{3}}{6}+a_{12} \frac{y}{2} \\
\beta_{y}= & a_{6} \frac{x^{2}}{2}+a_{7} \frac{x^{3}}{6}+a_{8} y+a_{9} x y+a_{10} \frac{y^{2}}{2} \\
& +a_{11} \frac{x y^{2}}{2}+a_{12} \frac{x}{2}
\end{aligned}
$$

The final field of displacements is obtained by adding the relations (15) and (17):

$$
\begin{aligned}
W= & a_{1}-a_{2} x-a_{3} y-a_{4} \frac{x^{2}}{2}-a_{5} \frac{x^{3}}{6} \\
& -a_{6} \frac{x^{2} y}{2}-a_{7} \frac{x^{3} y}{6}-a_{8} \frac{y^{2}}{2}-a_{9} \frac{x y^{2}}{2} \\
& -a_{10} \frac{y^{3}}{6}-a_{11} \frac{x y^{3}}{6}-a_{12} \frac{x y}{2} \\
\beta_{x}= & a_{2}+a_{4} \cdot x+a_{5} \frac{x^{2}}{2}+a_{6} \cdot x \cdot y+a_{7} \frac{x^{2} \cdot y}{2} \\
& +a_{9} \frac{y^{2}}{2}+a_{11} \frac{y^{3}}{6}+a_{12} \frac{y}{2} \\
\beta_{y}= & a_{3}+a_{6} \frac{x^{2}}{2}+a_{7} \frac{x^{3}}{6}+a_{8} \cdot y+a_{9} \cdot x \cdot y \\
& +a_{10} \frac{y^{2}}{2}+a_{11} \frac{x \cdot y^{2}}{2}+a_{12} \frac{x}{2}
\end{aligned}
$$

Matrix form the displacement field given by equations (18) reads as follows:

$$
\left\{\begin{array}{l}
\mathrm{W}(\mathrm{x}, \mathrm{y}) \\
\beta_{\mathrm{x}}(x, y) \\
\beta_{\mathrm{y}}(\mathrm{x}, \mathrm{y})
\end{array}\right\}=[\mathrm{f}(\mathrm{x} \cdot \mathrm{y})] \cdot\left\{\mathrm{a}_{\mathrm{i}}\right\}
$$

with,

$$
\left\{\mathrm{a}_{\mathrm{i}}\right\}^{\mathrm{T}}=<\mathrm{a}_{1}, \mathrm{a}_{2}, \mathrm{a}_{3}, \mathrm{a}_{4}, \mathrm{a}_{5}, \mathrm{a}_{6}, \mathrm{a}_{7}, \mathrm{a}_{8}, a_{9}, a_{10}, a_{11}, a_{12}>
$$

$$
[f(x, y)]=\left[\begin{array}{cccccccccccc}
1 & -x & -y & \frac{x^{2}}{2} & \frac{x^{3}}{6} & \frac{x^{2} y}{2} & \frac{x^{3} y}{6} & \frac{y^{2}}{2} & \frac{x^{2}}{2} & \frac{y^{3}}{6} & \frac{x^{3}}{6} & \frac{x^{y}}{2} \\
0 & 1 & 0 & x & \frac{x^{2}}{2} & x y & \frac{x^{2} y}{2} & 0 & \frac{y^{2}}{2} & 0 & \frac{y^{3}}{6} & \frac{y}{2} \\
0 & 0 & 1 & 0 & 0 & \frac{x^{2}}{2} & \frac{x^{3}}{6} & y & x y & \frac{y^{2}}{2} & \frac{x^{2}}{2} & \frac{x}{2}
\end{array} \mid\right.
$$

Knowing the nodal coordinates $\left(x_{i}, y_{i}\right)$ corresponding to the nodes $j(j=1 \ldots 4)$ and applying the relation (20) the vector of nodal displacements at the elementary level, is given as follows:

$$
\left\{q^{e}\right\}=\left[\begin{array}{l}
{\left[f\left(x_{1} \cdot y_{1}\right)\right]} \\
{\left[f\left(x_{2} \cdot y_{2}\right)\right]} \\
{\left[f\left(x_{3} \cdot y_{3}\right)\right]} \\
{\left[f\left(x_{4} \cdot y_{4}\right)\right]}
\end{array}\right]\left\{a_{i}\right\}(21)
$$

With,

$\left\{q^{e}\right\}^{T}=<w_{1}, \beta_{x 1}, \beta_{y 1}, w_{2}, \beta_{x 2}, \beta_{y 2}, w_{3}, \beta_{x 3}, \beta_{y 3}, w_{4}, \beta_{x 4}, \beta_{y 4}>[\mathrm{A}$

]$=\left[\begin{array}{l}{\left[\mathrm{f}\left(\mathrm{x}_{1} \cdot \mathrm{y}_{1}\right)\right]} \\ {\left[\mathrm{f}\left(\mathrm{x}_{2} \cdot \mathrm{y}_{2}\right)\right]} \\ {\left[\mathrm{f}\left(\mathrm{x}_{3} \cdot \mathrm{y}_{3}\right)\right]} \\ {\left[\mathrm{f}\left(\mathrm{x}_{4} \cdot \mathrm{y}_{4}\right)\right]}\end{array}\right]$ is the matrix of nodal coordinates. Its matrix form is developed in the appendix.

From equation (21), we deduce the value of parameters " $a_{i}$ " which are given by the system of equations: $\left\{a_{i}\right\}=[A]^{-1}\left\{q^{e}\right\}$

By replacing the parameters have the relationship given by (22) in the equation system (3.6), we obtain the relationship:

$$
\left\{\begin{array}{l}
\mathrm{W}(\mathrm{x}, \mathrm{y}) \\
\beta_{\mathrm{x}}(x, y) \\
\beta_{\mathrm{y}}(\mathrm{x}, \mathrm{y})
\end{array}\right\}=[\mathrm{f}(\mathrm{x} \cdot \mathrm{y})] \cdot[\mathrm{A}]^{-1} \cdot\left\{q^{e}\right\}
$$

which represents the matrix of interpolation functions $N_{i}$. By replacing in equations $(06), w(x, y)$ values of equation (19), the relationship strain - displacement takes the following expanded form:

$$
\left\{\begin{array}{l}
\mathrm{K}_{\mathrm{x}} \\
\mathrm{K}_{\mathrm{y}} \\
\mathrm{K}_{\mathrm{xy}}
\end{array}\right\}=\left[\begin{array}{cccccccccccc}
0 & 0 & 0 & 1 & x & y & x \cdot y & 0 & 0 & 0 & 0 & 0 \\
0 & 0 & 0 & 0 & 0 & 0 & 0 & 1 & x & y & x . y & 0 \\
0 & 0 & 0 & 0 & 0 & 2 x & x^{2} & 0 & 2 . y & 0 & y^{2} & 1
\end{array}\right] \cdot\left\{\mathrm{a}_{\mathrm{i}}\right\}
$$

Thus, the deformation matrix is given as follows: 


$$
[Q(x, y)]=\left[\begin{array}{cccccccccccc}
0 & 0 & 0 & 1 & x & y & x y & 0 & 0 & 0 & 0 & 0 \\
0 & 0 & 0 & 0 & 0 & 0 & 0 & 1 & x & y & x . y & 0 \\
0 & 0 & 0 & 0 & 0 & 2 x & x^{2} & 0 & 2 y & 0 & y^{2} & 1
\end{array}\right]
$$

\subsection{Elementary stiffness matrix}

The internal virtual work, elementary discredited is given by the expression:

$$
\left(\delta W_{\mathrm{int}}\right)^{e}=\int_{\mathrm{V}^{\mathrm{e}}} \delta\{\varepsilon\}^{\mathrm{T}} \cdot[\sigma] \cdot \mathrm{dV}
$$

$$
\text { Knowing that: }\{\varepsilon\}=\left[\mathrm{N}^{\prime}\right] \cdot\left\{\mathrm{q}^{\mathrm{e}}\right\}=[\mathrm{Q}(\mathrm{x} \cdot \mathrm{y})] \cdot[\mathrm{A}]^{-1}\left\{\mathrm{q}^{\mathrm{e}}\right\}
$$

And: $\{\sigma\}=[D] .\{\varepsilon\}$

And replacing in the expression (26), $\{\varepsilon\}$ and $\{\sigma\}$, their values given respectively in equations (27) and (28) yields:

$$
\left(\delta W_{\text {int }}\right)^{e}=\delta\left\{\mathrm{q}^{\mathrm{e}}\right\}^{\mathrm{T}} \int_{\mathrm{V}}[\mathrm{Q}(\mathrm{x} \cdot \mathrm{y})]^{\mathrm{T}} \cdot\left[\mathrm{A}^{-1}\right]^{\mathrm{T}} \cdot[\mathrm{D}] \cdot[\mathrm{Q}(\mathrm{x} \cdot \mathrm{y})] \cdot[\mathrm{A}]^{-1}\left\{\mathrm{q}^{\mathrm{e}}\right\} \mathrm{dV}
$$

Thus, the elementary stiffness matrix derived from the expression (29) is as follows:

$$
\left[K^{e}\right]=\int_{V}[\mathrm{Q}(\mathrm{xy})]^{\mathrm{T}}\left[A^{-1}\right]^{T}[D][\mathrm{Q}(\mathrm{xy})][A]^{-1} d V
$$

The expression (30) can be written:

$$
\left[K^{e}\right]=\left[A^{-1}\right]^{T} \int_{V}[Q(x \cdot y)]^{T}[D] \cdot[Q(x \cdot y)] \cdot d V \cdot[A]^{-1}=\left[A^{-1}\right]^{T}\left[K_{o}\right] \cdot[A]^{-1}
$$

The evaluation of the expression
$\left[\mathrm{K}_{0}\right]=\int_{V}[\mathrm{Q}(\mathrm{x} . \mathrm{y})]^{\mathrm{T}}[D] \cdot[\mathrm{Q}(\mathrm{x} \cdot \mathrm{y})] \cdot d V$ is determined by analytic integration of the various components of the resulting matrix product $[\mathrm{Q}(\mathrm{x} . \mathrm{y})]^{\mathrm{T}}[\mathrm{D}] \cdot[\mathrm{Q}(\mathrm{x} . \mathrm{y})]$. whose expressions take the form " $H_{\alpha x \beta}=C \cdot x^{\alpha} \cdot y^{\beta}$. The matrix [Ko] on the element "HIMEUR" is appended. So the matrix $[\mathrm{Ko}]$ is evaluated by analytical integration of values $\iint_{x} H_{\alpha x \beta}=\iint_{x} C \cdot x^{\alpha} \cdot y^{\beta}$. Finally, the elementary stiffness matrix to be considered at the assembly and construction of the global stiffness matrix of the structure is obtained after condensation of the matrix [Ke]. The static condensation on the degrees of freedom, concern the fictitious fourth node.

\section{Validation of the element "HIMEUR" \\ 4.1 Console-beam subjected to point load at its free end}

This test checks the behaviour of our simple bending element based on the slenderness ratio $(L / h)$. Indeed, in this case the bending test before the shear is dominant for ratios $L / h$ rates. At the free end, the beam is subjected in the direction " $O z$ " to $A$ point load of intensity $P=0.1$. It simulates a perfect fitting to the other end (see Figure 2).

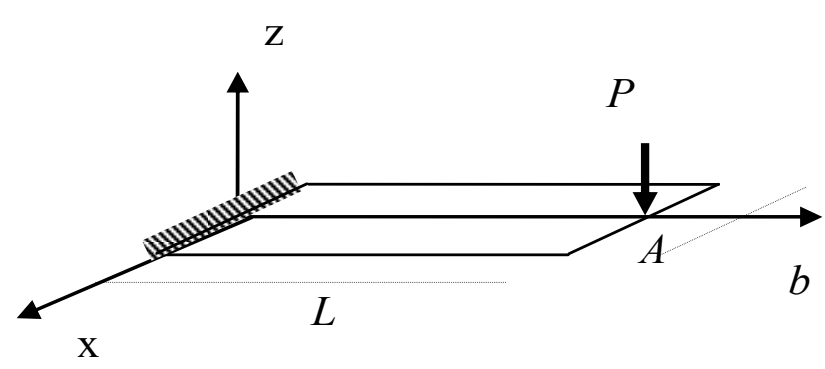

Figure 2 : Console-beam subjected to point load

Geometric data and mechanical loading are given in Table.1.

Table.1: geometric and mechanical loading data for the beam in simple bending

\begin{tabular}{ll}
\hline Length & $\mathrm{L}=10.0$ \\
Width & $\mathrm{b}=1.0$ \\
Thickness & $\mathrm{h}=(\mathrm{L} / 100 \approx \mathrm{L})$ \\
Young's modulus & $\mathrm{E}=1.2 \times 10^{6}$ \\
Poisson & $v=0.0$ \\
Loading & $\mathrm{P}=0.1$ \\
\hline
\end{tabular}

To see the influence of transverse shear on the behaviour of our element, we simulate in this test case, the displacement $" w$ " from point " $A$ " under the direction of "Oz" for several values of the ratio $L / h$. We then compare the results, first to the theoretical solution given by (4.1) of the beam theory and on the other hand, the behaviour of other triangular elements treated Guenfoud DSTM, ANST6, DKTM [GUE93]. The theoretical solution of the displacement " $w "$ from point " $A$ " in direction " $O z$ " is given as follows:

$w_{t}=\frac{4 \cdot P \cdot L^{3}}{E \cdot b \cdot h^{3}}\left[1+\frac{1}{2 \cdot k}\left(\frac{h}{L}\right)^{2}\right]$

The simulation results point " $A$ " in the direction "Oz" is given in Figure 3 and Table 2. 
Table 2: Displacement from point $A$ along the axis "Oz" console of the beam in simple bending

\begin{tabular}{cccccc}
\hline L/h & DSTM & ANST6 & DKTM & HIMEUR & $\begin{array}{c}\text { Theoretical } \\
\text { solution }\end{array}$ \\
\hline 1 & $5.1 \times 10^{-7}$ & $5.3 \times 10^{-7}$ & $3.1 \times 10^{-7}$ & $3.3 \times 10^{-7}$ & $5.3 \times 10^{-7}$ \\
2 & $2.9 \times 10^{-6}$ & $3.0 \times 10^{-6}$ & $2.5 \times 10^{-6}$ & $2.7 \times 10^{-6}$ & $3.1 \times 10^{-6}$ \\
3 & $9.0 \times 10^{-6}$ & $9.6 \times 10^{-6}$ & $8.4 \times 10^{-6}$ & $9.0 \times 10^{-6}$ & $9.6 \times 10^{-6}$ \\
4 & $2.0 \times 10^{-5}$ & $2.2 \times 10^{-5}$ & $2.0 \times 10^{-5}$ & $2.1 \times 10^{-5}$ & $2.2 \times 10^{-5}$ \\
5 & $4.0 \times 10^{-5}$ & $4.2 \times 10^{-5}$ & $3.9 \times 10^{-5}$ & $4.1 \times 10^{-5}$ & $4.3 \times 10^{-5}$ \\
10 & - & - & - & $3.3 \times 10^{-4}$ & $3.3 \times 10^{-4}$ \\
100 & 0.31329 & - & 0.31327 & 0.33303 & 0.3333 \\
\hline
\end{tabular}

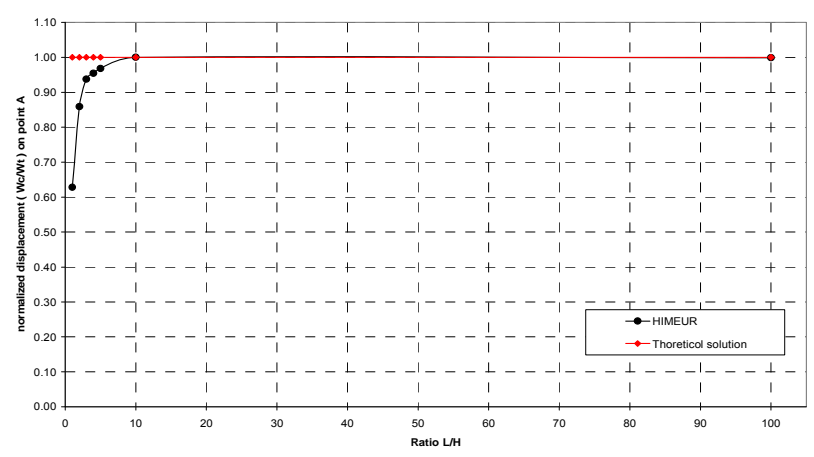

Figure 3 : Normalized Displacement of point A in pure bending

Figure 3 shows, in graphic form, the standard displacement of point " $A$ " in simple bending function of the ratio $L / h$ and comparing the behaviour of the element HIMEUR from the theoretical benchmark solution. We note that our element is very efficient for large slenderness $(L / h>10)$. It should be noted that its convergence to the solution is obtained with a mesh consisting of ten (10) elements. Table 2 also summarizes the results given by other existing triangular elements. We note here also that our element is robust to the elements DSTM, DKTM [GUE93] especially for L/h> 3 , since its behaviour is closer to the theoretical benchmark solution. Since it is very competitive with the element ANST6 [GUE93].

\subsection{Isotropic square plate}

This example was taken by many authors in the literature including [BAT90]. This is an isotropic square plate of side a and thickness h. In this work we simulate several scenarios based on the boundary conditions of the plate and the type of loading. It is in this test case to study the behaviour of the element HIMEUR considering different mesh sizes and several reports $\mathrm{a} / \mathrm{h}$ ".

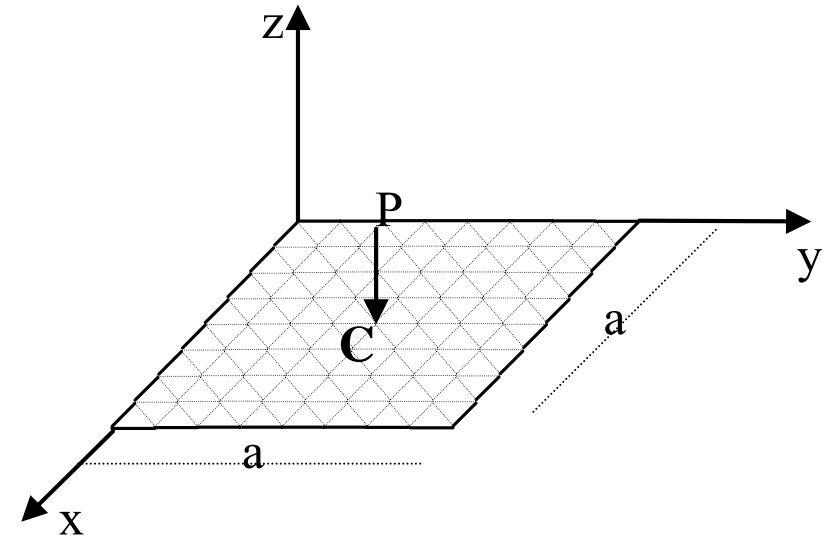

Figure 4 : isotropic square plate subjected to point load applied at its centre

The results concerning the displacement $" w "$ the central point $(C)$ of the plate is compared to analytical solutions for thin plate's for each case. As we proceed with comparisons with triangular elements in the existing literature, including elements SRI [SAB00], CO [BEL84], TRUMP (Argyris), DKT [BAT90].

4.2.1 Isotropic square plate requested by a point load applied at its centre

4.2.1.1. . Isotropic square plate simply supported on all four sides

Geometric and mechanical data are given in Table 3.

Tableau 3: geometric, mechanical and loading data for isotropic square plate

\begin{tabular}{ll}
\hline Length & $\mathrm{a}=2.0 \mathrm{~m}$ \\
Thickness & $\mathrm{h}=0.03 \mathrm{~m}$ \\
Young's modulus & $\mathrm{E}=210 \times 10^{9} \mathrm{~N} / \mathrm{m}^{2}$ \\
Poisson & $v=0.3$ \\
Loading & $\mathrm{P}=800 \mathrm{~N}$ \\
\hline
\end{tabular}

The theoretical solution of the displacement " $w$ " from point " $\mathrm{C}$ " along the direction of "Oz" is given by [BAT90] as follows:

$w_{t}=0.0116 \cdot \frac{P . a^{2}}{D} \quad$ with $\quad D=\frac{E \cdot h^{3}}{12\left(1-v^{2}\right)}$

The results of the displacement of point " $C$ " following direction "Oz" with different meshes are shown in Figure 5 and table 4 . 


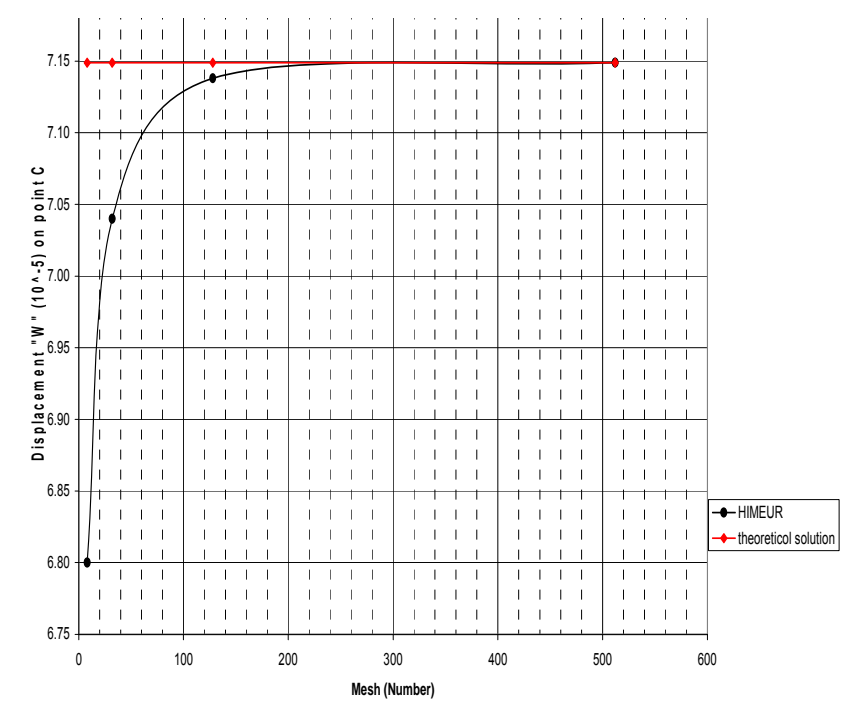

Figure 5 : Displacement "W " Point C - isotropic square plate, simply supported on all four sides, with concentrated load at point C -

Table.4: Normalized Displacement "Wp / Wt" Point C - isotropic square plate, simply supported on all four sides, with concentrated load at point $\mathbf{C}$ -

\begin{tabular}{|c|c|c|c|c|c|c|c|c|c|}
\hline $\begin{array}{l}\text { Mes } \\
\text { h }\end{array}$ & & $4 \times 4$ & & & $6 \times 6$ & & & $8 \times 8$ & \\
\hline $\mathrm{a} / \mathrm{h}$ & $\begin{array}{l}10 \\
0\end{array}$ & $\begin{array}{l}10 \\
00\end{array}$ & $\begin{array}{l}10 \\
00 \\
0\end{array}$ & $\begin{array}{l}10 \\
0\end{array}$ & $\begin{array}{l}10 \\
00\end{array}$ & $\begin{array}{l}10 \\
00 \\
0\end{array}$ & $\begin{array}{l}10 \\
0\end{array}$ & $\begin{array}{l}10 \\
00\end{array}$ & $\begin{array}{l}10 \\
00 \\
0\end{array}$ \\
\hline SRI & $\begin{array}{l}0.0 \\
70\end{array}$ & $\begin{array}{l}0.9 \\
\text { E- } \\
3\end{array}$ & $\begin{array}{l}0.9 \\
\text { E- } \\
5\end{array}$ & $\begin{array}{l}0.1 \\
34\end{array}$ & $\begin{array}{l}0.0 \\
01 \\
8\end{array}$ & $\begin{array}{l}1.9 \\
\text { E- } \\
5\end{array}$ & $\begin{array}{l}0.2 \\
07\end{array}$ & $\begin{array}{l}0.0 \\
03 \\
1\end{array}$ & $\begin{array}{l}3.1 \\
\text { E- } \\
5\end{array}$ \\
\hline $\mathrm{C}^{\mathrm{O}}$ & $\begin{array}{l}0.8 \\
98\end{array}$ & $\begin{array}{l}0.3 \\
82\end{array}$ & $\begin{array}{l}0.0 \\
08\end{array}$ & $\begin{array}{l}0.9 \\
60\end{array}$ & $\begin{array}{l}0.7 \\
81\end{array}$ & $\begin{array}{l}0.0 \\
83\end{array}$ & $\begin{array}{l}0.9 \\
78\end{array}$ & $\begin{array}{l}0.9 \\
16\end{array}$ & $\begin{array}{l}0.3 \\
09\end{array}$ \\
\hline $\begin{array}{l}\text { TR } \\
\text { UM } \\
\text { P }\end{array}$ & $\begin{array}{l}1.0 \\
17\end{array}$ & $\begin{array}{l}1.0 \\
16\end{array}$ & $\begin{array}{l}1.0 \\
16\end{array}$ & $\begin{array}{l}1.0 \\
09\end{array}$ & $\begin{array}{l}1.0 \\
07\end{array}$ & $\begin{array}{l}1.0 \\
07\end{array}$ & $\begin{array}{l}1.0 \\
06\end{array}$ & $\begin{array}{l}1.0 \\
04\end{array}$ & $\begin{array}{l}1.0 \\
04\end{array}$ \\
\hline $\begin{array}{l}\mathrm{DK} \\
\mathrm{T}\end{array}$ & $\begin{array}{l}1.0 \\
03\end{array}$ & $\begin{array}{l}1.0 \\
03\end{array}$ & $\begin{array}{l}1.0 \\
03\end{array}$ & $\begin{array}{l}1.0 \\
02\end{array}$ & $\begin{array}{l}1.0 \\
02\end{array}$ & $\begin{array}{l}1.0 \\
02\end{array}$ & $\begin{array}{l}1.0 \\
01\end{array}$ & $\begin{array}{l}1.0 \\
01\end{array}$ & $\begin{array}{l}1.0 \\
01\end{array}$ \\
\hline $\begin{array}{l}\text { HIM } \\
\text { EU } \\
\text { R }\end{array}$ & $\begin{array}{l}0.9 \\
84\end{array}$ & $\begin{array}{l}0.9 \\
84\end{array}$ & $\begin{array}{l}0.9 \\
84\end{array}$ & $\begin{array}{l}0.9 \\
97\end{array}$ & $\begin{array}{l}0.9 \\
97\end{array}$ & $\begin{array}{l}0.9 \\
97\end{array}$ & $\begin{array}{l}1.0 \\
00\end{array}$ & $\begin{array}{l}1.0 \\
00\end{array}$ & $\begin{array}{l}1.0 \\
00\end{array}$ \\
\hline
\end{tabular}

Figure 5 shows, in graphic form, displacement from point " $C$ " with different meshes. We note the good performance of our element, since it converges rapidly towards the analytical solution of reference.
Table 4 also includes the values of the normalized displacement "Wp/Wt" of point $C$ of some elements of triangular thin plate, for different meshes and several reports " $a / h$ " and highlights the quality of results obtained by the element HIMEUR to these elements. Again this element is more robust to the elements SRI [SAB00], $\mathrm{C}^{\mathrm{O}}$ [BEL84], TRUMP (Argyris), whatever the mesh or the ratio " $a / h "$ and very competitive with the DKT element [BAT90].

\subsubsection{4.2.1.2 Isotropic square plate clamped at its four sides}

We resume the test case for this example in Figure 3 with the same geometrical and mechanical data of the material, but simulating a perfect fitting of the plate on all four sides. The theoretical solution of the displacement " $w$ " from point " $C$ " along the direction of "Oz" is given by [BAT90] as follows:

$$
w_{t}=0.0056 . \frac{P . a^{2}}{D} \quad \text { with } \quad D=\frac{E \cdot h^{3}}{12\left(1-v^{2}\right)}
$$

The results of the displacement of point " $C$ " following direction "Oz" with different meshes are shown in Figure 6.

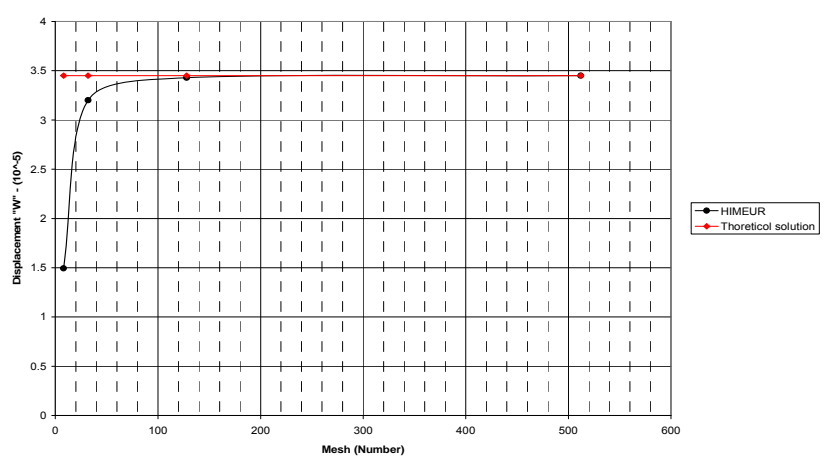

Figure6: Displacement"W"Point - isotropic square plate clamped at its four sides, with concentrated load at point C -

The Figure 6 shows, graphically, the displacement from point "C" with different meshes. Just as the previous test cases, our element present, there is also a good performance, since it converges rapidly towards the analytical solution of reference.

\subsubsection{Isotropic square plate requested by a uniformly distributed load}

We resume for this test case the sample plate of Figure 3 that we are seeking a uniformly distributed load of intensity $\mathrm{q}=60 \mathrm{~T} / \mathrm{m}^{2}$. 


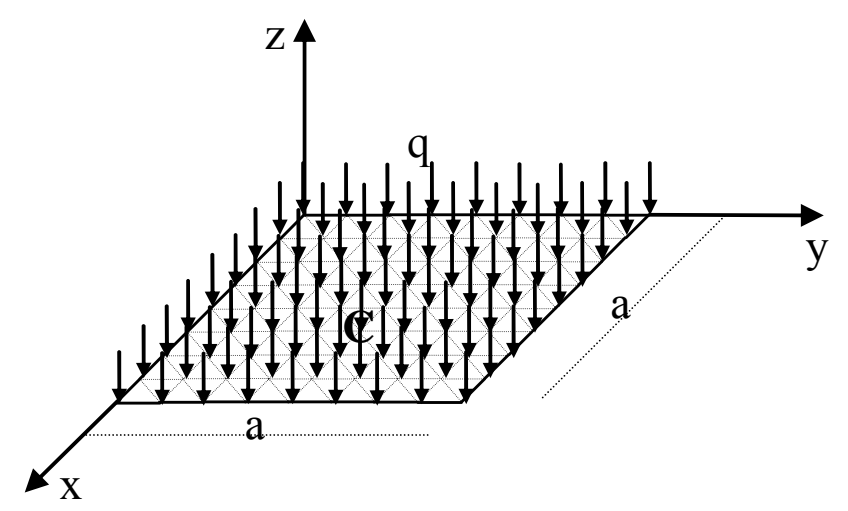

Figure 7: isotropic square plate subjected to a uniformly distributed load.

The theoretical solution of the displacement " $w$ " from point " $C$ " along the direction of "Oz" is given for the case of a plate simply supported by the formula (35) and for the case of the plate embedded in the formula (36):

$w_{t}=0.004062 \cdot \frac{q \cdot a^{4}}{D}$

With $\quad D=\frac{E \cdot h^{3}}{12\left(1-v^{2}\right)}$

$w_{t}=0.00126 \cdot \frac{q \cdot a^{4}}{D}$

With

$$
D=\frac{E \cdot h^{3}}{12\left(1-v^{2}\right)}
$$

The simulation results of displacement of point " $C$ " following direction "Oz" with different meshes are shown in Figures 8 and 9. Figure 8 summarizes the results for the case of a plate simply supported and those relating to Figure 9 the plate clamped along its four sides. We note that for both test cases, our element behaves well, since it is characterized by rapid convergence to the analytical solution.

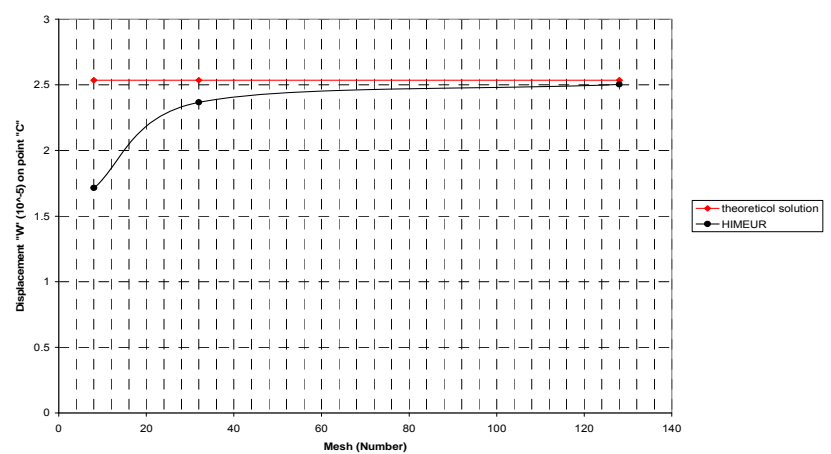

Figure 8: Displacement 'W' Point $C$ - isotropic square plate simply supported on all four sides with a uniformly distributed load -

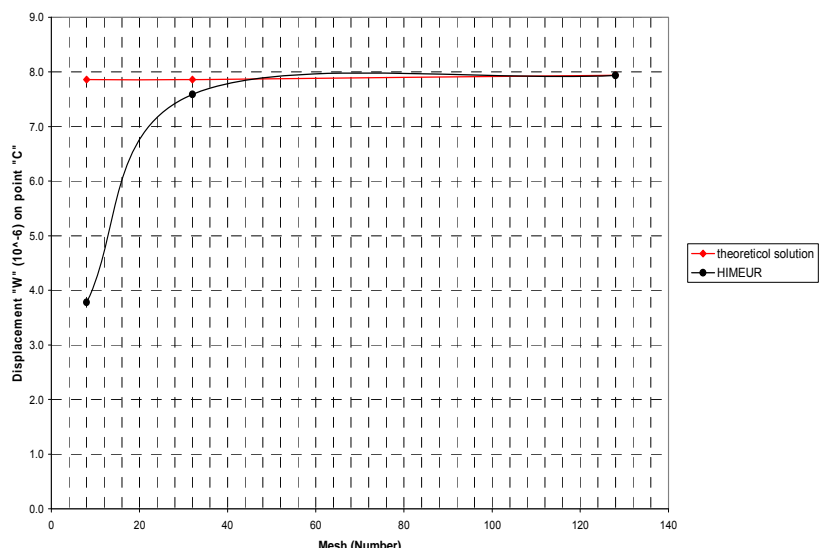

Figure 9: Displacement "W" Point C -- Isotropic square plate clamped at its four sides, with a uniformly distributed load -

\subsection{Skew isotropic plate}

It is for this test, a plate of isotropic skew (angle $60^{\circ}$ ) (Figure 10) subjected to a uniform load $\mathrm{p}$ with two simple supports $(\mathrm{W}=0)$ and two free edges. Geometric and mechanical data are given in Table 5 .

Table 5: geometric and mechanical data for the isotropic skew plate $\left(60^{\circ}\right)$

\begin{tabular}{ll}
\hline Side length & $\mathrm{L}=100.0$ \\
\hline Thickness & $\mathrm{h}=0.1$ \\
Young's modulus & $\mathrm{E}=1000$ \\
Poisson & $v=0.31$ \\
\hline
\end{tabular}

This problem treated by [BAT90] for the analysis of quadrilateral elements and DSQ Q4 $\gamma$ is used to evaluate the convergence of our element. To do this we considered grids of $2 \times 2,4 \times 2,8 \times 2,16 \times 2$ elements per side. The reference solution, obtained by a finite difference scheme [RAZ73], is given by formula 37 .

$$
\begin{aligned}
& w_{\text {ref }}=0.007945 . \frac{P \cdot L^{2}}{D} \\
& \text { With } \quad D=\frac{E \cdot h^{3}}{12\left(1-v^{2}\right)}
\end{aligned}
$$




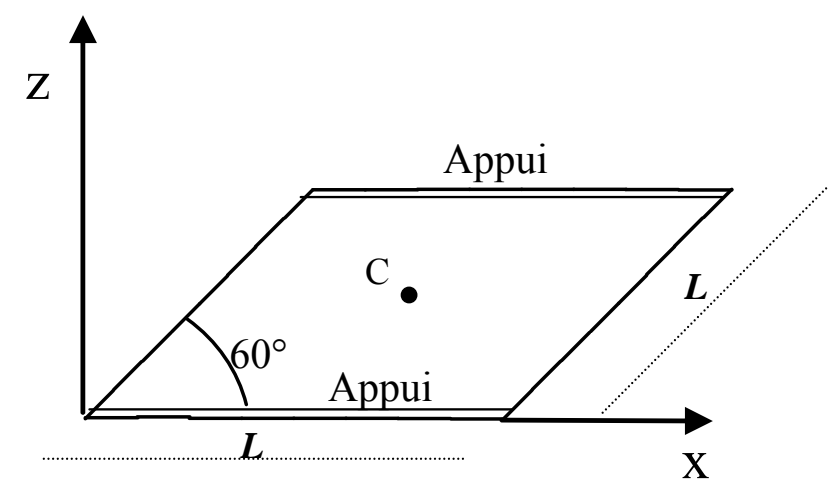

Figure 10: isotropic skew plate $\left(60^{\circ}\right)$ with free edges

The results of displacements obtained by the element HIMEUR are illustrated by the Figure 11. We've also worn for purposes of comparison, the results given by the elements and quadrilateral DSQ Q4 $\gamma$ [BAT90]. We observe a monotonic convergence for all three items with a convergence at the top of the element "HIMEUR".

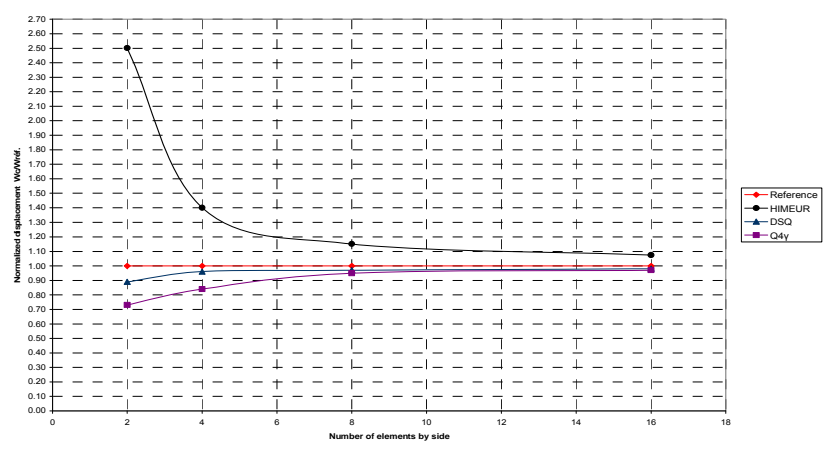

Figure 11 : Displacement normalized "Wp / Wref." the central point - isotropic skew plate with free edges-

\subsection{Tests ROBINSON}

There are two tests proposed by Robinson [ROB78] to study the behaviour of a triangular element loaded in bending and torsion constrained.

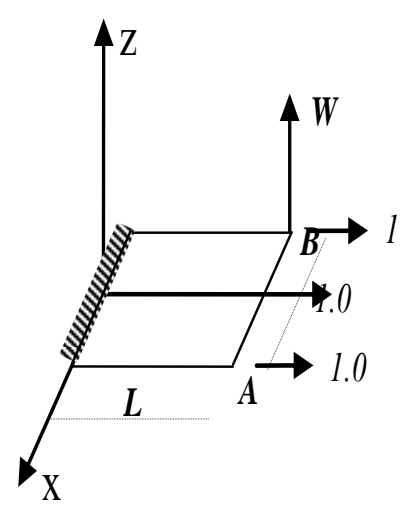

A - 12.1 - bending constrained

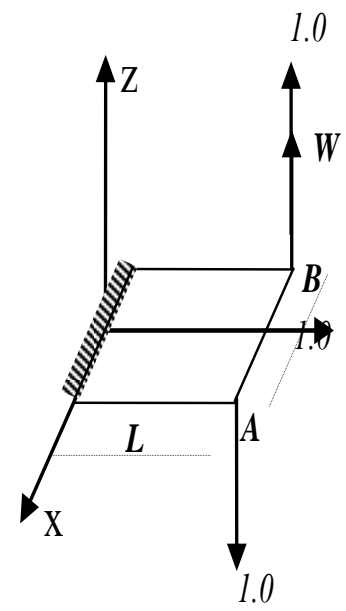

B - 12.2 - twisting constrained

Figure 12: Console-beam subjected to tests ROBINSON

The geometrical and mechanical characteristics of the material are given in Table 6. We study the influence of the ratio $\mathrm{L} / \mathrm{h}$ (the length varies from $1 \mathrm{xh}$ to $10000 \mathrm{xh}$ ) on the move "W" from point "A" for both types of solicitations.

Table6: geometric, mechanicalmaterial for the beam-console submitted to test ROBINSON

\begin{tabular}{ll}
\hline Side length & $\mathrm{L}=$ Variable \\
Width & $\mathrm{b}=1.0$ \\
Thickness & $\mathrm{h}=0.05$ \\
Young's modulus & $\mathrm{E}=1.0 \times 10^{7}$ \\
Poisson & $\mathrm{v}=0.25$
\end{tabular}

Test "A" for the behaviour of the beam-console under the action of two pairs $\mathrm{M}_{\mathrm{y}}=1.0$ applied to the nodes of its free end. This is the bending constrained. Test "B" for the action of two concentrated loads $\mathrm{P}_{\mathrm{z}}=-1.0$ and $\mathrm{P}_{\mathrm{z}}=1.0$ respectively applied to the same nodes. This is the twisting constrained. The reference solution (BENCHMARK) on triangular elements is extracted from [GUE90].

Table 7: Test "A" - Bending constrained - displacement "W" from point "A"

\begin{tabular}{lllllll}
\hline L & ANST3 & ANST6 & HCT & DKT & HIMEUR & BENCHMARK \\
\hline 0.05 & 0.00000174 & 0.0000064 & - & - & 0.000008022 & - \\
0.5 & 0.00087300 & 0.0011800 & - & - & 0.00092053 & - \\
1 & 0.00356000 & 0.0038100 & 0.0010520 & 0.002105 & 0.00235240 & 0.0028 \\
2 & 0.00935000 & 0.0100000 & 0.0015790 & 0.006580 & 0.00614230 & 0.0056 \\
3 & 0.01480000 & 0.0162000 & 0.0010520 & 0.009870 & 0.00938960 & 0.0084 \\
4 & 0.02020000 & 0.0222000 & 0 & 0.013160 & 0.01215900 & 0.0112 \\
5 & 0.02550000 & 0.0280000 & -0.0052600 & 0.016450 & 0.01477200 & 0.0140
\end{tabular}




\begin{tabular}{lllllll}
6 & 0.03070000 & 0.0339000 & -0.0018420 & 0.019740 & 0.01735700 & 0.0168 \\
7 & 0.03600000 & 0.0397000 & - & 0.023030 & 0.01995100 & 0.0196 \\
8 & 0.04120000 & 0.0455000 & -0.0028940 & 0.026320 & 0.02256200 & 0.0224 \\
9 & 0.04600000 & 0.0513000 & - & 0.029620 & 0.02518800 & 0.0252 \\
10 & 0.05170000 & 0.0571000 & -0.0044730 & 0.032900 & 0.02782800 & 0.0280 \\
11 & - & - & - & 0.036190 & 0.03047800 & 0.0308 \\
12 & - & - & -0.0057890 & 0.039480 & 0.03313700 & 0.0336 \\
25 & 0.12970000 & 0.1433000 & - & - & 0.06805900 & - \\
50 & 0.25970000 & 0.2869000 & - & - & 0.13567000 & - \\
500 & 2.59850000 & 2.6540000 & - & - & 1.35530000 & - \\
\hline
\end{tabular}

Table 8: Test "B" - Twisting constrained - displacement "W" from point "A"

\begin{tabular}{lllllll}
\hline L & ANST3 & ANST6 & HCT & DKT & HIMEUR & BENCHMARK \\
\hline 0.05 & 0.00000116 & 0.00000383 & - & - & 0.00000100 & - \\
0.5 & 0.00043800 & 0.00088300 & - & - & 0.00045531 & - \\
1 & 0.00178000 & 0.00252000 & 0.0010660 & 0.001866 & 0.00186770 & 0.002666 \\
2 & 0.00467000 & 0.00555000 & 0.0024000 & 0.004400 & 0.00550220 & 0.005333 \\
3 & 0.00743000 & 0.00847000 & 0.0030660 & 0.006800 & 0.00840630 & 0.007999 \\
4 & 0.01010000 & 0.01130000 & 0.0034660 & 0.009200 & 0.01095800 & 0.010666 \\
5 & 0.01270000 & 0.01420000 & 0.0037330 & 0.011733 & 0.01344500 & 0.013333 \\
6 & 0.01540000 & 0.01710000 & 0.0042666 & 0.014000 & 0.01593200 & 0.015999 \\
7 & 0.01800000 & 0.02000000 & - & 0.016400 & 0.01842900 & 0.018666 \\
8 & 0.02060000 & 0.02290000 & 0.0050660 & 0.018933 & 0.05093700 & 0.021333 \\
9 & 0.02320000 & 0.02570000 & - & 0.021333 & 0.02345500 & 0.023999 \\
10 & 0.02580000 & 0.02860000 & 0.0061330 & 0.023600 & 0.02598100 & 0.026666 \\
11 & - & - & - & 0.025866 & 0.02851200 & 0.029333 \\
12 & - & - & 0.0070660 & 0.028266 & 0.03104700 & 0.031999 \\
25 & 0.06489000 & 0.07170000 & - & - & 0.06419500 & - \\
50 & 0.12986000 & 0.14350000 & - & - & 0.12817000 & - \\
500 & 1.29930000 & 1.43270000 & - & 1.28090000 & - \\
\hline & & & - & & & \\
\hline
\end{tabular}

Tables 7 and 8 and Figures 13 and 14 show the displacement " $W$ " from point " $A$ " according to the ratio $\mathrm{L} / \mathrm{h}$ and comparing the behaviour of the element HIMEUR compared to the reference solution (BENCHMARK ) and the results given by other existing triangular elements ANST3 [GUE90] ANST6 [GUE90], HCT, DKT [BAT90]. The detailed study of the results highlights the good performance of the element HIMEUR. Indeed the results achieved are very close to the reference solution for both constrained for bending torsion constrained and this regardless of the length "L". It should be noted that this result is obtained with a moderate mesh consisting only of four triangular elements. Moreover, the element HIMEUR appears stronger than all the elements taken as a basis for comparison, although the element DKT for the situation constrained bending and to a lesser extent the ANST3 element for the situation of twist embarrassed him are competitive. Figures 7 and 8 illustrate graphically these findings. 


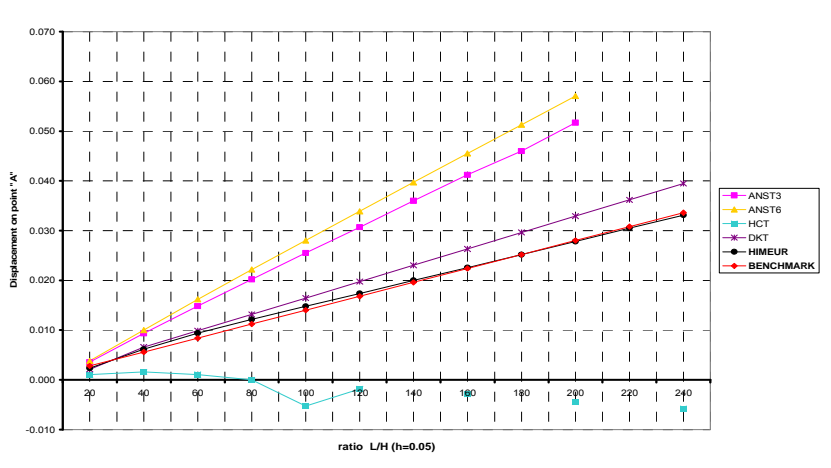

Figure 13: Test "A" - Bending constrained - displacement "W" from point "A"

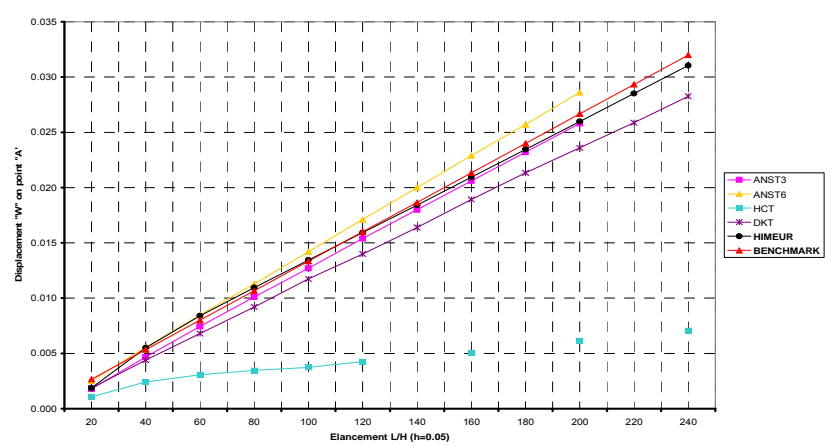

Figure 14: Test "B" - Twisting constrained - displacement "W" from point "A"

\section{Conclusion}

We presented in this work a finite element triangular inflected perspective of linear static analysis and dynamic analysis for nonlinear geometric structures curves (arcs and shells). The approach, concepts and development techniques used have resulted in a finite element competitive, robust and effective for the treatment of thin plates. It remains to continue his maturation into a reliable and efficient tool to address the calculation of all situations of shells, from thin to thick, deep or low loaders. This is something that has certain advantages which advocate their use. The presence of the fictitious node and the adoption of the approach "deformation" have the opportunity to enrich the displacement field, thus greater accuracy in the approximation of the solution, avoiding the complexity of the classical theories. The reduction of elementary stiffness matrices by the technique of static condensation, "Action on the degrees of freedom relating to fictitious node, avoiding systems of equations to be solved, enormous, thus saving time machine not negligible. The use of analytical integration in the evaluation of the stiffness matrix, gave our element behavior performance. This result was remarkable in the convergence tests carried out where we are seeing a rapid trend towards the solution unlike isoperimetric elements (using numerical integration).

\section{REFERENCES BIBLIOGRAPHIQUES}

[1] [BAT80] Batoz J. L., Bath KJ, Ho L.W., A study of three node triangular plate bending elements. Int. J. Num. Meth. Eng. 1980;15:1771-812.

[2] [BAT90] Batoz J. L., Dhatt G., Modélisation des structures par éléments finis, vol.1, Solides Elastiques, Vol 2 : Poutres et plaques, Hermes, Paris, 1990, Volume 1, 455 pages, Volume 2, 483 pages.

[3] [BEL99] Belarbi M. T., Charif A. Développement d'un nouvel élément hexaédrique simple basé sur le modèle en déformation pour l'étude des plaques minces et épaisses, Revue européenne des éléments finis, 1999 pp 135-157.

[4] [BEL00] Belarbi M. T., Développement de nouveaux éléments à modèle en déformation : Application linéaire et non linéaire, Thèse de Doctorat, Univ. Constantine (Algérie), 2000.

[5] [BEL84] Belytschko, T. ONG, J.S.J., LIU, WK.,KENNEDY, J.M., Hourglass control in linear and nonlinear problems, Compute methods in applied mechanics and engineering, 1984, Vol 43, pp 251276.

[6] [CLO65] Clough R.W. \& Tocher JL.., Finite element stiffness matrixes for analysis of plate bending, Proceeding of first conference Matrix methods in structural mechanics, Wright-Pattersonm Qir force bqsem Ohiom 1965. 515-812.

[7] [FRE98] François Frey, Traité de génie civil de l'école polytechnique fédérale de Lausane - Volume 3 - Analyse des structures et milieux continus mécanique des solides, Presses polytechniques et universitaires romandes $\mathrm{CH}-1015,1998$.

[8] [GUE90] Guenfoud M., Deux éléments triangulaires nouveaux pour l'analyse linéaire et non linéaire géomètrique des coques, Thèse de doctorat, Institut national des sciences appliquées de Lyon (France), Novembre 1990, 346p

[9] [GUE93] Guenfoud M., Présentation de l'élément DSTM pour le calcul linéaire des coques d'épaisseur quelconque, Ann. l'ITBTP, 1993; 515: 25-52.

[10] [HIM08] Himeur M., Développement d'éléments membranaires nouveaux d'élasticité plane basés sur la formulation en déformation, Thèse de magistère, Université de Guelma (Algérie), Département de Génie Civil, Novembre 2008, 104p

[11] [HGM08] Himeur M. \& Guenfoud M., Elément fini triangulaire nouveau à noeud central perturbé en formulation déformation avec drilling rotation, CIFMA'03, 21-23 April 2008, Alep, Syrie

[12] [IBR93] Ibrahimbegovic A., et Frey F. et Rebora B., Une approche unifiée de la modélisation des structures complexes: les éléments finis avec degré de liberté de rotation, LSC, Rapport Interne 93/10, Ecole polytechnique fédérale de Lausanne (Suisse), Juin 1993.

[13] [PRO00] Providas E. and Kattis M. A., An assessment of two fundamental flat triangular shell elements with drilling rotation, Computers and structures 77, pp 129-139, 2000. 
[14] [RAZ73] Razake A., Program of triangular bending elements with derivative smo0thing, IJNME, Vol. 6, p. 333-343, 1973.

[15] [ROB78] Robinson J.., element evaluation. A set of assessment points and standards tests Proc. Element method in the commercial environment, Vol. 1, pp 217-248, Oct. 1978.

[16] [SAB83] Sabir A.B., A new class of finite elements for plane elasticity problems, CAFEM $7^{\text {th }}$, Int. conf. Struct. Mech. In reactor Technology, Chicago, 1983.

[17] [SAB85] Sabir A.B., A rectangular and triangular plane elasticity element with drilling degrees freedom, chapter 9 in proceeding of the $2^{\text {nd }}$ International conference on variational methods in engineering, Southampton University, Springer verlag, Berlin, 1985, pp 17-25.

[18] [SAB95] Sabir A.B., A Sfendji, Triangular and Rectangular Plane Elasticity Finite Elements, ThinWalled struct., 21-1995, pp 225-232.
[19] [SAB00] Sabourin F.m Salle F., Calcul des structures par éléments finis, Barres - Poutres Elasticité plane Axisymétrique Plaques - coques non linéarité, Chapitre IV, INSA Lyon, 2000, 17 pages.

[20] [SAR91] Jean-Luc SARF, La condensation statique dans felina (nouvelle édition), Rapport Interne LSC 91/22, 1991.

[21] [TEO82] Teodorecu Paul, Grands éléments finis"GEF" pour l'élasticité plane, Thèse $\mathrm{n}^{\circ} 462$ de doctorat présentée au département de génie civil, Ecole polytechnique fédérale de Lausane Suisse, 1982

[22] [YUA88] Yuan F.,Miller RE., A rectangular finite element for moderately thick flat plate, Computer.Struct.1988;30:1375-87. 


\section{Appendices}

A.1. Matrix of nodal coordinates

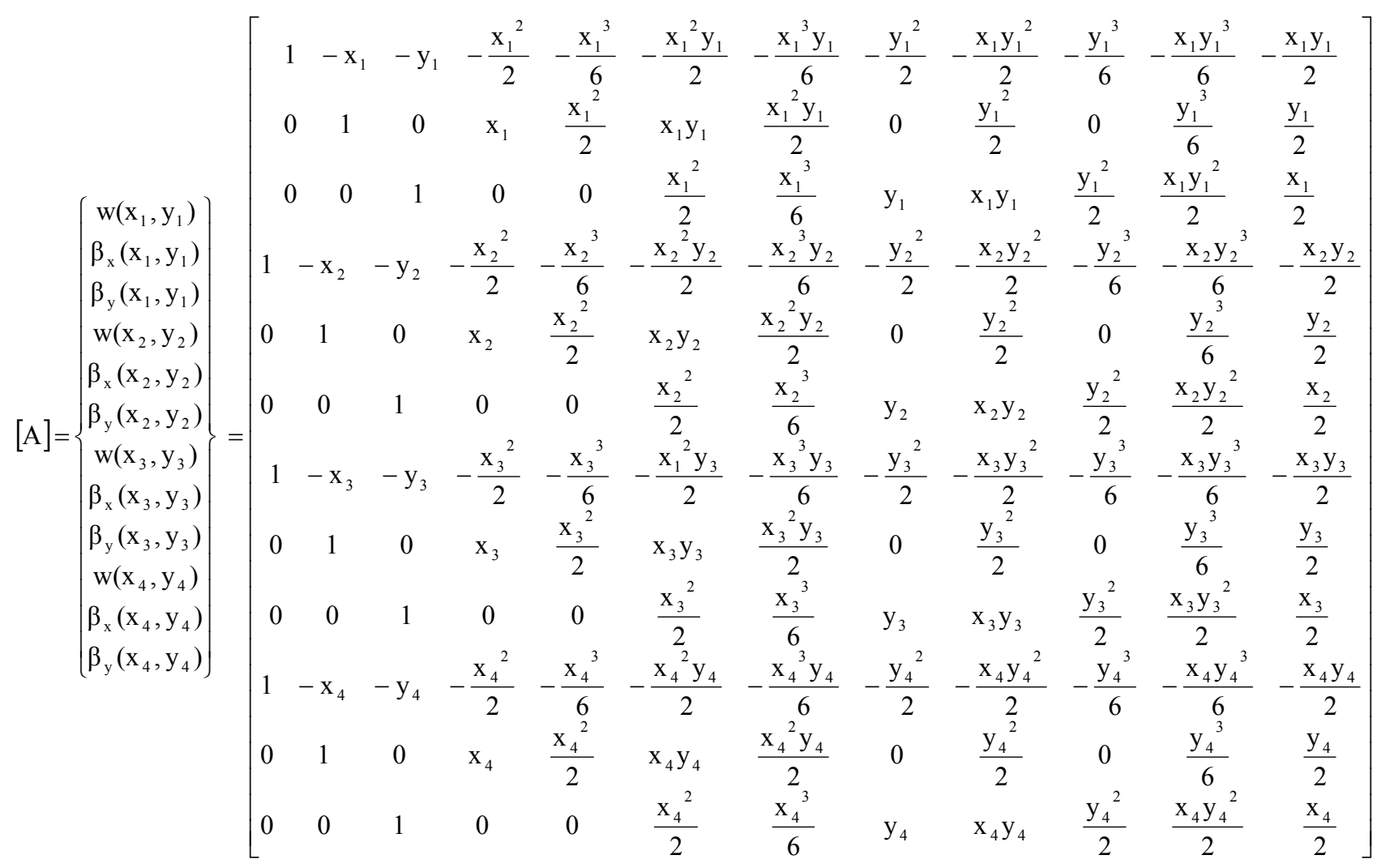

\section{A.2. Matrix [ Ko ]}

- General form

$[\mathrm{Ko}]=\frac{\mathrm{Eh}^{3}}{12\left(1-v^{2}\right)}\left(\begin{array}{ccc}0 & 0 & 0 \\ 0 & 0 & 0 \\ 0 & 0 & 0 \\ 1 & 0 & 0 \\ \mathrm{x} & 0 & 0 \\ \mathrm{y} & 0 & 2 \mathrm{x} \\ \mathrm{xy} & 0 & \mathrm{x}^{2} \\ 0 & 1 & 0 \\ 0 & \mathrm{x} & 2 \mathrm{y} \\ 0 & \mathrm{y} & 0 \\ 0 & \mathrm{xy} & \mathrm{y}^{2} \\ 0 & 0 & 1\end{array}\right) \cdot\left[\begin{array}{cccc}1 & v & 0 \\ v & 1 & 0 \\ 0 & 0 & \frac{(1-\mathrm{v})}{2}\end{array}\right] \cdot\left(\begin{array}{cccccccccccc}0 & 0 & 0 & 1 & \mathrm{x} & \mathrm{y} & \mathrm{xy} & 0 & 0 & 0 & 0 & 0 \\ 0 & 0 & 0 & 0 & 0 & 0 & 0 & 1 & \mathrm{x} & \mathrm{y} & \mathrm{xy} & 0 \\ 0 & 0 & 0 & 0 & 0 & 2 \mathrm{x} & \mathrm{x}^{2} & 0 & 2 \mathrm{y} & 0 & \mathrm{y}^{2} & 1\end{array}\right) \mathrm{dxdy}$ 
- Expanded form before analytic integration

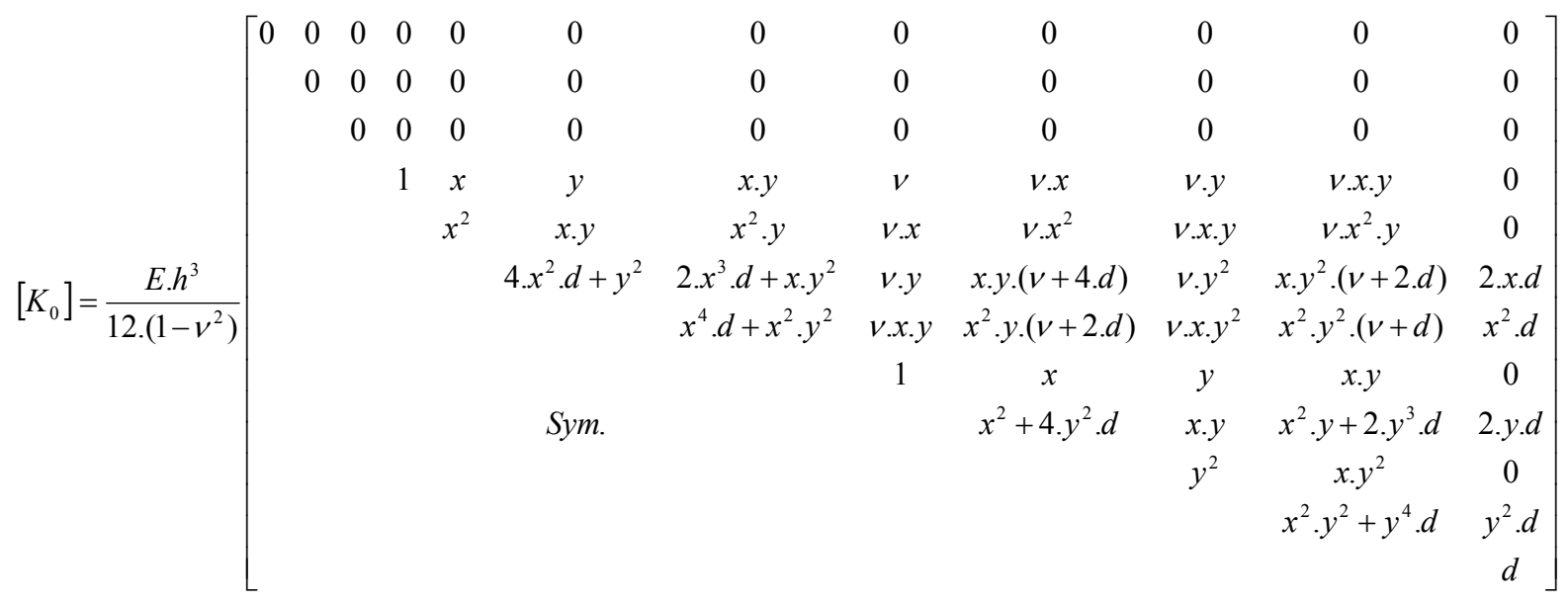

$$
\begin{aligned}
& \text { with : } \\
& d=\frac{(1-v)}{2}
\end{aligned}
$$

- Expanded form after analytic integration

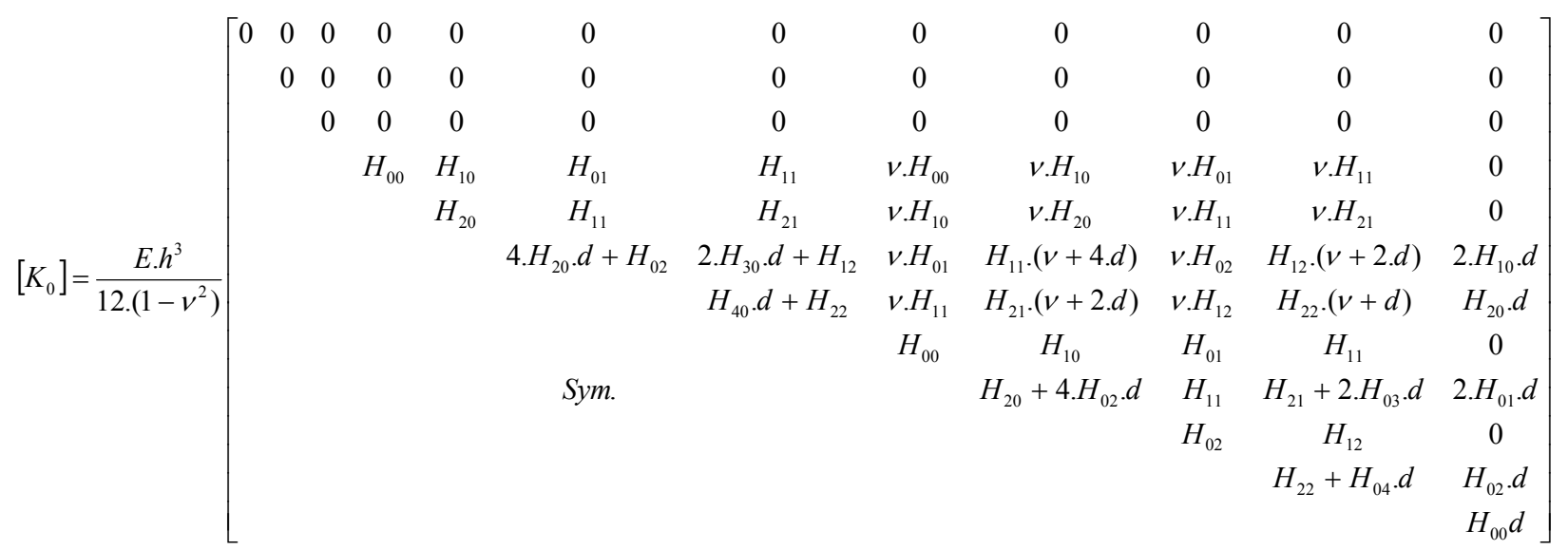

with : $\quad H_{\alpha \beta}=\iint X^{\alpha} Y^{\beta} d x \cdot d y$ 